\title{
A Gaussian Test for Stationarity in a Mixed Frequency Regression for More Power
}

\author{
Tilak Abeysinghe ${ }^{1}$ and Gulasekaran Rajaguru*2 \\ ${ }^{1}$ Department of Economics, National University of Singapore, Singapore \\ ${ }^{2}$ Bond Business School, Bond University, Robina, QLD, Australia
}

\begin{abstract}
Unit root tests that are in common use today tend to over-reject the stationarity of economic ratios like the consumption-income ratio or rates like the average tax rate. The meaning of a unit root in such bounded series is not very clear. We use a mixed-frequency regression technique to develop a test for the null hypothesis that a series is stationary. The focus is on regression relationships, not so much on individual series. What is noteworthy about this moving average (MA) unit root test, denoted as $\mathrm{z}(\mathrm{MA})$ test, based on a variance-difference, is that, instead of having to deal with non-standard distributions, it takes testing back to normal distribution and offers a way to increase power without having to increase the sample size substantially. Monte Carlo simulations show minimal size distortions even when the AR root is close to unity and the test offers substantial gains in power relative to some popular tests against near-null alternatives in moderate size samples. Applying this test to log of consumption-income ratio of 21 OECD countries shows that the $\mathrm{z}(\mathrm{MA})$ test favors stationarity of 15 series, KPSS test 8 series, Johansen test 6 series and ADF test 5 series.
\end{abstract}

Keywords null of stationarity; MA unit root; variance difference

\section{Introduction}

Economic theory often requires ratios like consumption share of income, investment share of GDP and the average tax rate to be stationary; see, for example, King et al. (1991), and references therein. Even if these series appear to be non-stationary (Harvey, 1989), the meaning of a unit root in them is not very clear. More generally, what is of interest is whether a regression provides stable parameters with stationary residuals regardless of the nature of the non-stationarity of the individual series. Although there are a number of tests that use the null of stationarity, many test statistics for unit-roots and cointegration that are currently in use have non-standard distributions and often have low power against autoregressive roots close to unity; see Maddala and Kim (1998) for a survey of the unit root literature. Kim and Choi (2017) have questioned the validity of previous unit root verdicts on many time series that have ignored the problem of low power.

We revisit this old problem with the objective of presenting a test for the null of stationarity of the deviations from a long-run relationship. This will allow us to test it against different alternatives such as autoregressive (AR) unit roots, fractional integration, structural breaks and policy interventions. Financial time series may also exhibit multiple non-stationaries (Reschenhofer, 2004) or explosive bubbles (Harsha and Ismail, 2017). In this exercise we consider only the AR unit root alternative and defer the evaluation of other alternatives to future work. The test

\footnotetext{
*Corresponding author. E-mail: rgulasek@bond.edu.au.
} 
also brings the distribution back to normal distribution and at the same time offers a substantial improvement in power.

The test presented here focuses on a moving average (MA) unit root. Although the idea of testing for an MA unit root is not new (Tanaka, 1990), the importance of such tests needs to be re-emphasized. Being a behavioral outcome, an AR unit root could be somewhat illusive, see Hamilton (1994, Sec. 15.4) and Phillips (2010), whereas an MA unit root can be created by over-differencing a stationary process, therefore, easier to pin down. The basic idea underlying our test procedure emanated from a mixed-frequency regression presented in Abeysinghe (1998) and temporal aggregation, systematic sampling and dynamic relationships studied in Rajaguru (2004), Rajaguru and Abeysinghe (2008) and Rajaguru et al. (2018). The test procedure involves a simple data transformation to obtain a mixed frequency regression and focuses on the difference in error variances of the original model and the transformed model.

\section{Methodology}

Consider the following model that Leybourne and McCabe (1994) extended from Harvey (1989) and Kwiatkowski et al. (1992) to test the null of stationarity against an alternative of difference stationarity:

$$
\begin{aligned}
\phi(L) y_{t} & =\alpha_{t}+\beta t+\varepsilon_{t}, \\
\alpha_{t} & =\alpha_{t-1}+\eta_{t}, \quad \alpha_{0}=\alpha,
\end{aligned}
$$

where $\varepsilon_{t} \stackrel{\text { i.i.d. }}{\sim} \mathrm{N}\left(0, \sigma_{\varepsilon}^{2}\right), \eta_{t} \stackrel{\text { i.i.d. }}{\sim} \mathrm{N}\left(0, \sigma_{\eta}^{2}\right)$, both of which are independent of each other, and $\phi(L)=$ $1-\phi_{1} L-\ldots-\phi_{p} L^{p}$ with roots outside the unit circle. This has the following $\operatorname{ARIMA}(p, 1,1)$ representation:

$$
\Delta y_{t}=\beta+\phi_{1} \Delta y_{t-1}+\ldots+\phi_{p} \Delta y_{t-p}+u_{t}-\theta u_{t-1},
$$

where $u_{t} \stackrel{i . i . d .}{\sim} \mathrm{N}\left(0, \sigma^{2}\right)$ with $\sigma^{2}=\sigma_{\varepsilon}^{2} / \theta, \theta=\left(\lambda-\left(\lambda^{2}+4 \lambda\right)^{1 / 2}+2\right) / 2$ and $\lambda=\sigma_{\eta}^{2} / \sigma_{\varepsilon}^{2}$ is the signal-to-noise ratio. If $\sigma_{\eta}^{2}=\lambda=0$ and $\theta=1$, model (2) collapses to a stationary $\operatorname{AR}(p)$ process. Alternatively, $\Delta y_{t}$ in (2) has a non-invertible $\operatorname{ARMA}(p, 1)$ representation. To test the null of stationarity a number of researchers formulated tests based on $H_{0}: \sigma_{\eta}^{2}=0$ vs $H_{1}: \sigma_{\eta}^{2}>0$. These are in effect tests of an MA unit root and the distributions involved are in general nonstandard (Kwiatkowski et al., 1992; Saikkonen and Luukkonen, 1993; Leybourne and McCabe, 1994; Choi, 1994; Breitung, 1995). As $\lambda$ increases, $\theta$ approaches zero and we get a standard unit root autoregression. In this exercise the ARIMA model in (2) forms the basis of our test.

As stated earlier our test is based on a mixed frequency regression procedure that helps in increasing the power of the test at a given sample size. Abeysinghe $(1998,2000)$ applied a transformation to a dynamic regression to forecast quarterly GDP with monthly external trade of Singapore without converting monthly data to quarterly frequency as is usually done. Basically, the procedure is developed for a situation where the dependent variable is observed at a low frequency and the independent variable at a higher frequency. The standard practice in this situation is to convert the high frequency variable into the low frequency by aggregating or averaging, whichever is appropriate. Occasionally the low frequency variable may be converted to the high frequency using some interpolation methods such as the Chow-Lin procedure (Abeysinghe and Rajaguru, 2004). The mixed frequency procedures retain the data in their own frequencies. This tends to improve forecasts and helps in deriving impulse responses at the higher frequency. 
We can easily adapt the mixed frequency procedure for the purpose of this exercise.To illustrate the idea, (2) can be written as

$$
u_{t}=\theta u_{t-1}-\beta+\phi(L) \Delta y_{t} .
$$

If $u_{t}$ is assumed to be observed at low frequency intervals $t=m, 2 m, \ldots, T$, where $m \geq 2$ is a positive integer, and $\Delta y_{t}$ is observed at high frequency intervals $t=1,2, . ., T$, the basic idea of the mixed frequency regression is to transform $u_{t-1}$ in (3) to $u_{t-m}$ such that all the observations of $\Delta y_{t}$ are retained in the regression. This transformation is easily obtained by multiplying (3) through by the polynomial $\theta(L)=1+\theta L+\ldots+\theta^{m-1} L^{m-1}$. The transformed model can be written as

$$
\theta(L) \phi(L) \Delta y_{t}=\theta(1) \beta+V_{t},
$$

where $V_{t}=\theta(L)(1-\theta L) u_{t}=u_{t}-\theta^{m} u_{t-m}$.

Now note that under the null $H_{0}: \theta=1, \operatorname{Var}\left(V_{t}\right)=2 \sigma^{2}$ and under the alternative $H_{1}$ : $|\theta|<1, \operatorname{Var}\left(V_{t}\right)=\left(1+\theta^{2 m}\right) \sigma^{2}<2 \sigma^{2}$. Therefore, $\operatorname{Var}\left(V_{t}\right)-2 \sigma^{2}$ forms the basis of our test. By transforming the test of $\theta$ into a test of $\operatorname{Var}\left(V_{t}\right)$ we can arbitrarily increase the distance between the null and the alternative simply by increasing $m$ whereby extra gains in power is made possible. For example, a test of $\theta=1$ when $\theta=0.9$ translates into comparing $2 \sigma^{2}$ against $\operatorname{Var}\left(V_{t}\right)=1.43 \sigma^{2}$ for $m=4$ and $\operatorname{Var}\left(V_{t}\right)=1.08 \sigma^{2}$ for $m=12$. This transformation allows us to formulate a number of test statistics that follow standard distributions.

We denote $\operatorname{Var}\left(V_{t}\right)$ by $\sigma_{m}^{2}$ to indicate its dependence on $m$. Given that we can obtain consistent estimates of the parameters in (2), we can compute $\hat{\sigma}^{2}$ and $\hat{\sigma}_{m}^{2}$ and then form the test statistic $\sqrt{T}\left(\hat{\sigma}_{m}^{2}-2 \hat{\sigma}^{2}\right)$ to test $\theta=1$ against $|\theta|<1$. Using the subscript $T$ to indicate the dependence on the sample size, we can define $\hat{\sigma}_{T}^{2}=(1 / T) \sum_{t=1}^{T} \hat{u}_{t}^{2}, \hat{V}_{t}=\hat{u}_{t}-\hat{\theta}^{m} \hat{u}_{t-m}$ and $\hat{\sigma}_{m, T}^{2}=(1 / T) \sum_{t=1}^{T} \hat{V}_{t}^{2}$. The following theorem establishes the asymptotic distribution of the test statistic.

Theorem 1. Given that $u_{t} \stackrel{i . i . d .}{\sim} N\left(0, \sigma^{2}\right)$ and assuming $E\left(u_{t}^{4}\right)=\mu_{4}<\infty$, under the null hypothesis of $\theta=1, \sqrt{T}\left(\hat{\sigma}_{m, T}^{2}-2 \hat{\sigma}_{T}^{2}\right) \stackrel{d}{\longrightarrow} N\left(0,4 \sigma^{4}\right)$.

Proof. see Appendix A.

The test procedure in practice is the following. Assuming $p+1$ pre-sample values $y_{-p}, \ldots, y_{0}$ are available, estimate the $\operatorname{ARMA}(p, 1)$ for $\Delta y_{t}$ in (2) by maximum likelihood (ML) and obtain $\hat{\theta}$ and $\hat{\sigma}^{2}=\sum t=1^{T} \hat{u}_{t}^{2} /(T-p-2)$ (these are provided by standard computer software procedures). Then obtain $\hat{V}_{t}=\hat{u}_{t}-\hat{\theta}^{m} \hat{u}_{t-m}$ and $\left.\hat{\sigma}_{m}^{2}=\sum_{t=m+1}^{T} \hat{V}_{t}-\overline{\hat{V}}\right)^{2} /\left(T_{a}-1\right)$, where $T_{a}=T-m$ is the effective sample size and $\overline{\hat{V}}$ is the sample mean of $\hat{V}_{t}$. (Note that the subtraction of $\overline{\hat{V}}$ is not essential in large samples.) Then compute $z=\sqrt{T}\left(\hat{\sigma}_{m}^{2}-2 \hat{\sigma}^{2}\right) / 2 \hat{\sigma}^{2}$ and reject the null hypothesis $\theta=1$ if $z \leq c$ where $c$ is a left-hand critical value from the standard normal distribution. We term this as $\mathrm{z}(\mathrm{MA})$ test to differentiate it from a $\mathrm{z}(\mathrm{AR})$ test that can be obtained by extending our test procedure to the AR unit root case. We extended the test procedure to the AR unit root case, which provides a generalization to the variance-ratio test developed by Lo and MacKinlay $(1988,1989)$. Although the extension works very well (better power) in the AR(1) case, we still need further work on the $\operatorname{AR}(p)$ case. See Wang et al. (2010) for an application of the variance ratio test with a random walk null hypothesis to the index of Shanghai stock exchange.

One problem that we may encounter in estimating $\theta$ is the pile-up problem of the ML estimator at the invertibility boundary (e.g., Breidt et al., 2006). This is an issue that is being 
addressed by a number of researchers. In particular, Davis and Dunsmuir (1996) have explored the possibility of using a Laplace likelihood with a local maximizer to estimate an MA(1) model with a unit root or a near unit root. It is very likely that an estimator of $\theta$ that will overcome the pile-up problem will emerge in due course. From a practical point of view, the pile-up problem of the Gaussian likelihood may not be a serious problem. Although over-differenced stationary series produce $\theta=1$, AR unit-root series are likely to produce a $\theta$ well away from unity. Many empirical estimates of $\theta$ from non-stationary series hardly exceed 0.9 and do not exhibit the presence of the pile-up problem.

\section{Monte Carlo Results}

In this section we present the results of a Monte Carlo experiment to highlight the size and power properties of the test under near unit root alternatives. Since our primary interest is in cointegrating relationships we use the following model for the simulation exercise.

$$
\begin{aligned}
y_{t} & =\delta_{0}+\delta_{1} x_{t}+z_{t}, \\
x_{t} & =x_{t-1}+\varepsilon_{t} . \\
\left(1-\phi_{1} L\right) \Delta z_{t} & =\beta+(1-\theta L) u_{t},
\end{aligned}
$$

where $u_{t}$ and $\varepsilon_{t}$ are generated from independent $N(0,1)$ distributions. If $\delta_{1}$ is known then (5) represents the case of testing for the stationarity of a known long run relationship. If $\delta_{0}$ and $\delta_{1}$ are estimated then (5) represents the case of testing for the stationarity of regression residuals. The size of the test is obtained when $\theta=1$. For this we set $\phi_{1}=0.5,0.9,0.95$. For power, we need near unit root alternatives. For this we use $\theta=0.8$ with $\phi_{1}=0.5,0.9,0.95$ and $\theta=0.95$ with $\phi_{1}=0.5,0.9$. In the case of known $z_{t}, \beta=1$ and when $z_{t}$ is the estimated residuals $\beta=0$ and $\delta_{0}=\delta_{1}=1$. Appendix B provides a comprehensive survey of power of various tests available. Nevertheless, for comparison, we also compute power of three commonly used tests, KPSS, ADF, and Johansen. The above same parameter setting is used for the KPSS test. For the ADF and Johansen tests the alternative hypothesis is stationarity. This is obtained when $\theta=1$ and equation (5) simply reduces to an $\operatorname{AR}(1)$ process for $z_{t}$. Therefore, to have near unit root alternatives that correspond to above $\theta$ values we set $\phi_{1}=0.8$ and 0.95 .

Table 1 shows that some size distortions occur as $m$ increases especially when regression residuals are involved. Nevertheless, these distortions are rather minimal. Although the test relies on the T-consistency of $\hat{\sigma}$, the use of estimated $\theta$ tends to produce size distortions when $m$ increases. We observe that such size distortions do not occur if we set $\theta=1$ in the computation of $\hat{\sigma}_{m}^{2}$ from residuals obtained from a pure AR fit. Careful examination of individual replications showed that the problem emanates from non-convergence of $\hat{\theta}$ in some replications.

Table 2 shows power when testing a known long run relationship or a single series (Johansen test is omitted in this table as it is not designed for single series) and Table Table 3 when the long run relationship is estimated. To accommodate Johansen test results in the table and to display the table in portrait layout on the page we have deleted results for $m=2$. Improvement in power from $m=2$ to $m=4$ is similar to that of Table 2. There are a number of points to note in the tables. First, the power of the $\mathrm{z}(\mathrm{MA})$ test in sample sizes 100 and 200 is quite impressive even when $m=2$ relative to KPSS and ADF tests and those reported in Appendix B (5\% values are highlighted in the tables for easy comparison). However, the gain in power when $m$ increases beyond 4 is rather small. Therefore, based on both size and power properties an $m=4$ seems to 
Table 1: Size of the $z(M A)$ test for an MA unit root (2000 replications).

\begin{tabular}{|c|c|c|c|c|c|c|c|c|c|c|c|c|}
\hline \multirow[t]{2}{*}{$T$} & \multicolumn{3}{|c|}{$m=2$} & \multicolumn{3}{|c|}{$m=4$} & \multicolumn{3}{|c|}{$m=6$} & \multicolumn{3}{|c|}{$m=8$} \\
\hline & $1 \%$ & $5 \%$ & $10 \%$ & $1 \%$ & $5 \%$ & $10 \%$ & $1 \%$ & $5 \%$ & $10 \%$ & $1 \%$ & $5 \%$ & $10 \%$ \\
\hline \multicolumn{13}{|c|}{$\begin{array}{l}\text { Known long-run relation or single series } \\
\qquad \phi_{1}=0.5, \theta=1\end{array}$} \\
\hline 100 & 0.007 & 0.031 & 0.062 & 0.016 & 0.045 & 0.078 & 0.022 & 0.046 & 0.089 & 0.024 & 0.052 & 0.088 \\
\hline 200 & 0.006 & 0.035 & 0.074 & & 0.041 & & & 0.048 & & .029 & 0.057 & 0.089 \\
\hline 300 & 005 & 023 & 067 & & 0.045 & & & 0.049 & 994 & 028 & .057 & 098 \\
\hline 500 & 0.002 & 0.030 & 0.068 & 0.013 & 0.054 & 0.095 & 0.022 & 0.060 & 0.096 & 0.027 & 0.061 & 0.104 \\
\hline \multicolumn{13}{|c|}{$\phi_{1}=0.9, \theta=1$} \\
\hline 100 & 0.007 & 0.037 & 0.079 & 0.007 & 0.036 & 0.074 & 0.009 & 0.036 & 0.075 & 0.010 & 0.038 & 0.073 \\
\hline 200 & & 0.035 & 0 & & 0.044 & & & 040 & & 16 & 044 & 079 \\
\hline 300 & 009 & 0.041 & 0 & & 039 & & & 043 & & 017 & 039 & 072 \\
\hline 500 & 0.008 & 0.037 & 0.083 & .013 & 0.037 & 0.089 & 0.017 & 0.041 & 0.088 & 0.019 & 0.046 & 0.090 \\
\hline \multicolumn{13}{|c|}{$\phi_{1}=0.95, \theta=1$} \\
\hline 100 & & 0.054 & & & 0.057 & & 0.027 & & & 0.029 & 0.058 & 0.094 \\
\hline 200 & 014 & 0.047 & & & 049 & & & & & & .046 & \\
\hline 30 & 015 & 0 & & & .041 & & & & & 022 & 055 & \\
\hline 500 & 0.006 & 0.038 & 0.078 & 0.006 & 0.048 & 0.089 & 0.008 & 0.040 & 0.095 & 0.011 & 0.049 & 0.097 \\
\hline \multicolumn{13}{|c|}{$\begin{array}{c}\text { Regression residuals } \\
\phi_{1}=0.5, \theta=1\end{array}$} \\
\hline 100 & 014 & 0.065 & 0.129 & .023 & 0.073 & 0.136 & 0.021 & 0.074 & & 0.028 & 0.081 & 0.139 \\
\hline 200 & 009 & 0.049 & & & 0.066 & & & $0.0^{\prime}$ & & 25 & 0.075 & 134 \\
\hline 300 & 016 & 053 & & 7 & 0.059 & & 0.0200 & 0.068 & 0 & 0.032 & 0.081 & 131 \\
\hline 500 & 0.009 & 0.042 & 0.097 & 0.013 & 0.063 & 0.115 & 0.017 & 0.066 & 0.112 & 0.025 & 0.079 & 0.135 \\
\hline \multicolumn{13}{|c|}{$\phi_{1}=0.9, \theta=1$} \\
\hline 100 & 017 & 0.084 & 0.1 & .018 & 0.079 & 0.150 & 0.014 & 0.08 & & 0.018 & 0.076 & 0.144 \\
\hline 20 & 0.011 & 0.065 & 0.074 & .018 & 0.074 & 0.12 & 0.01 & 0.071 & & 0.017 & 0.066 & 0.122 \\
\hline 300 & 0.014 & 0.065 & 0.136 & 0.016 & 0.074 & 0.14 & 0.019 & 0.066 & 0.122 & 0.018 & 0.069 & 0.134 \\
\hline 500 & 0.011 & 0.056 & 0.117 & 0.016 & 0.066 & 0.123 & 0.022 & 0.074 & 0.137 & 0.019 & 0.062 & 0.125 \\
\hline \multicolumn{13}{|c|}{$\phi_{1}=0.95, \theta=1$} \\
\hline 100 & 0.020 & 0.10 & & & 0.088 & 0.170 & 0.024 & 0.091 & & 0.029 & 0.083 & \\
\hline 200 & & & & & 0.076 & & & 0.092 & & 0.021 & 0.087 & 0.154 \\
\hline 300 & & 0.075 & & & 0.081 & & 0.027 & 0.082 & & 0.025 & 0.085 & 0.147 \\
\hline 500 & 0.017 & 0.073 & 0.131 & 0.022 & 0.076 & 0.137 & 0.020 & 0.070 & 0.133 & 0.025 & 0.081 & 0.142 \\
\hline
\end{tabular}

be a reasonable choice. We also examined the results by over-fitting the AR order upto $p=3$; the results remain very much unaffected by this over-fitting.

Second, when the AR parameter $\phi_{1}$ increases there is a substantial gain in power. This feature is shared by the KPSS test as well. Increasing autoregressive persistence amplifies the non-stationary behavior of the series locally and adds to the power of $\mathrm{z}(\mathrm{MA})$ and KPSS tests. Third, although power drops when $\theta=0.95$ the $\mathrm{z}(\mathrm{MA})$ test retains high power relative to other tests in sample sizes 100 and 200. Again, increasing autoregressive persistence is advantages to the test. Many tests in use today do not perform well when the alternative is pushed closer to the null value. Fourth, there is no systematic substantial drop in power when residual series are used with the $\mathrm{z}(\mathrm{MA})$ test. Although the KPSS test also does not show a substantial drop in power, it is not so with the ADF test.

It is worth making a comparison of the results in Table 1, Table 2 and Table 3 with the 
Table 2: Power of $\mathrm{z}(\mathrm{MA}), \mathrm{KPSS}$, and ADF tests (2000 replications) for known long-run relation or single series.

\begin{tabular}{|c|c|c|c|c|c|c|c|c|c|c|c|c|c|c|c|}
\hline \multirow[t]{2}{*}{$T$} & \multicolumn{3}{|c|}{$\mathrm{z}(\mathrm{MA}): m=2$} & \multicolumn{3}{|c|}{$m=4$} & \multicolumn{3}{|c|}{$m=8$} & \multicolumn{3}{|c|}{ KPSS } & \multicolumn{3}{|c|}{$\mathrm{ADF}$} \\
\hline & $1 \%$ & $5 \%$ & $10 \%$ & $1 \%$ & $5 \%$ & $10 \%$ & $1 \%$ & $5 \%$ & $10 \%$ & $1 \%$ & $5 \%$ & $10 \%$ & $1 \%$ & $5 \%$ & $10 \%$ \\
\hline \multicolumn{13}{|c|}{$\phi_{1}=0.5, \theta=0.8$} & \multicolumn{3}{|c|}{$\phi_{1}=0.8$} \\
\hline 100 & 0.497 & 0.590 & 0.646 & 0.622 & 0.670 & 0.700 & 0.647 & 0.642 & 0.706 & 0.210 & 0.520 & 0.676 & 0.077 & 0.304 & 0.497 \\
\hline 200 & 793 & 864 & 888 & 895 & 0.912 & 0.921 & 0.935 & 0.913 & 0.921 & 0.465 & 0.739 & 832 & .452 & 0.834 & 0.9 \\
\hline 300 & 936 & 0.963 & 0.973 & 981 & 0.985 & 0.989 & 985 & 0.988 & 0.988 & 0.593 & 0.796 & 0.881 & .866 & 0.988 & 1.000 \\
\hline 500 & 0.993 & 0.997 & 0.997 & 0.998 & $\begin{array}{c}0.999 \\
\phi_{1}=\end{array}$ & $\begin{array}{r}0.999 \\
=0.9, \theta\end{array}$ & $\begin{array}{c}0.999 \\
=0.8\end{array}$ & 0.999 & 0.999 & 0.761 & 0.908 & & 1.000 & 1.000 & 1.000 \\
\hline 100 & 0.809 & 0.901 & 0.933 & 0.911 & 0.945 & 0.959 & 0.953 & 0.963 & 0.970 & 0.404 & 0.712 & 0.846 & & & \\
\hline 200 & 909 & 0.963 & 973 & 971 & 0.984 & 0.98 & 987 & 0.993 & 0.9 & 0.584 & 0.841 & & & & \\
\hline 300 & 0.959 & 0.981 & 990 & 987 & 0.993 & 0.994 & 0.994 & 0.996 & 0.996 & 0.677 & 0.868 & 0.9 & & & \\
\hline 500 & 0.993 & 0.997 & 0.999 & 0.998 & $\begin{array}{c}0.998 \\
\phi_{1}=\end{array}$ & $\begin{array}{c}1.000 \\
0.95, \theta\end{array}$ & $\begin{array}{r}000 \\
0.8\end{array}$ & 1.000 & 1.000 & 0.793 & 0.932 & 0.967 & & & \\
\hline 100 & 0.770 & 0.889 & 0.925 & 0.932 & 0.957 & 0.965 & 0.960 & 0.969 & 0.973 & 0.519 & 0.798 & 0.900 & & & \\
\hline 200 & 0.946 & 0.987 & 994 & 993 & 0.994 & 0.995 & 0.996 & 0.997 & 0.998 & 0.706 & 0.916 & 0.9 & & & \\
\hline 300 & 0.989 & 0.995 & 0.999 & 000 & 1.000 & 1.000 & 1.000 & 1.000 & 1.000 & 0.768 & 0.924 & 0.966 & & & \\
\hline 500 & 1.000 & 1.000 & 1.000 & 1.000 & $\begin{array}{c}1.000 \\
\phi_{1}=\end{array}$ & $\begin{array}{r}1.000 \\
0.5, \theta\end{array}$ & $\begin{array}{r}1.000 \\
=0.95\end{array}$ & 1.000 & 1.000 & 0.857 & 0.960 & 0.982 & & ${ }_{1}=$ & \\
\hline 100 & 0.119 & 0.250 & 0.358 & 0.227 & 0.434 & 0.521 & 0.491 & 0.592 & 0.641 & 0.035 & 0.175 & 0.294 & 0.023 & 0.109 & 0.209 \\
\hline 200 & 0.173 & 0.372 & 0.508 & 0.473 & 0.637 & 0.704 & 0.733 & 0.806 & 0.834 & 0.167 & 0.390 & 0.512 & 0.085 & 0.303 & 0.490 \\
\hline 300 & 0.245 & 0.452 & 0.591 & 0.612 & 0.761 & 0.825 & 0.856 & 0.897 & 0.909 & 0.311 & 0.558 & 0.671 & 0.210 & 0.581 & 0.783 \\
\hline 500 & 0.390 & 0.619 & 0.753 & 0.823 & $\begin{array}{c}0.910 \\
\phi_{1}=\end{array}$ & $\begin{array}{c}0.941 \\
0.9, \theta\end{array}$ & $\begin{array}{r}0.958 \\
=0.95\end{array}$ & 0.973 & 0.978 & 0.563 & 0.766 & 0.844 & 0.706 & 0.959 & 0.992 \\
\hline 100 & 0.758 & 0.819 & 0.8 & 0.850 & 0.893 & 0.911 & 0.897 & 0.915 & 0.927 & 0.166 & 0.474 & 0.636 & & & \\
\hline 20 & 755 & 0.819 & 0 & 56 & 0.892 & 0.914 & 0.905 & 0.929 & 0.9 & 0.360 & 0.637 & 0.758 & & & \\
\hline 30 & 735 & 0.80 & 0.8 & 48 & 0.893 & 0.9 & 0.912 & 0.931 & $0 . \subseteq$ & 0.435 & 0.696 & 0.796 & & & \\
\hline 500 & 0.684 & 0.775 & 0.824 & 0.841 & 0.883 & 0.910 & 0.915 & 0.934 & 0.951 & 0.648 & 0.847 & 0.901 & & & \\
\hline
\end{tabular}

variance-difference (VD) test that Breitung (1994) developed. This asymptotically normal VD test, derived based on the assumption of an $\operatorname{MA}(q)$ process, produces desirable small-sample size and power properties for finite order MA processes. However, when the process involved was an $\operatorname{ARMA}(1,1)$ that needed to be approximated by a finite order MA process, Breitung observed substantial size distortions. For example, when $\phi_{1}=0.9(\theta=1), T=100$, and $\alpha=5 \%$, Breitung reported empirical size of 0.907 for $\mathrm{MA}(4)$ approximation and 0.215 for $\mathrm{MA}(12)$ approximation. This problem does not arise in our test as we can see in Table 1. The tables also show that near $\mathrm{AR}$ unit root cases which manifest with low power in AR unit root tests come under control in this MA unit root test.

\section{Is Consumption-Income Ratio Non-Stationary?}

Economic theory posits that the consumption-income ratio or the average propensity to consume (APC) is stationary. Nevertheless, popular unit root tests in use often render the verdict that this ratio is non-stationary. We revisit this by testing the stationarity of $\log (\mathrm{APC})$ in 21 OECD countries using the above three popular tests and the $\mathrm{z}(\mathrm{MA})$ test. Table 4 presents the results. In the computation of the $\mathrm{z}(\mathrm{MA})$ statistic, as a check against the near common factor problem we 
Table 3: Power of z(MA), KPSS, ADF, and Johansen tests (2000 replications) for estimated long-run relation or single series.

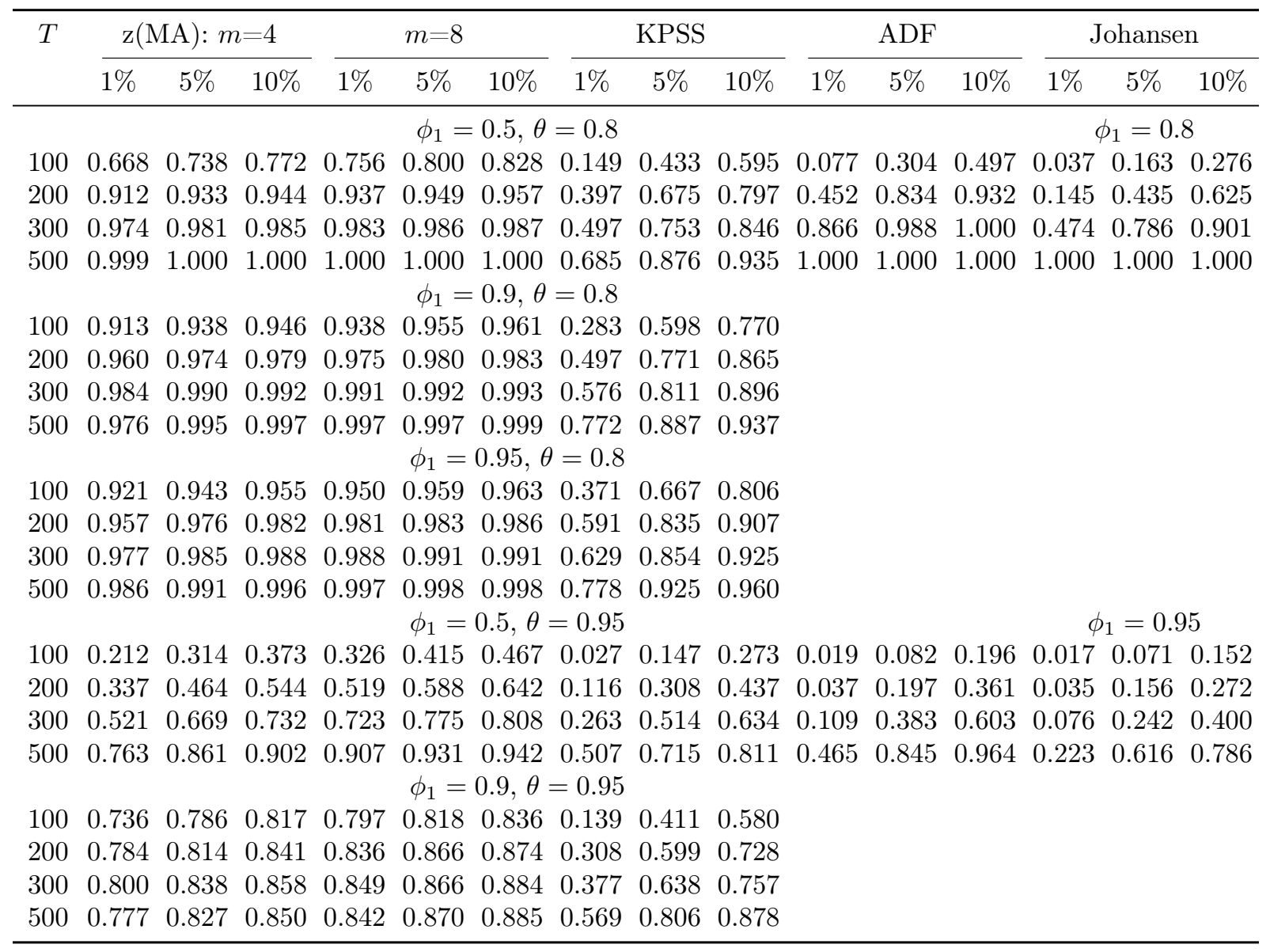

advise fitting an $\operatorname{AR}(p)$ model to $y_{t}$ first and then an $\operatorname{ARMA}(p, 1)$ to $\Delta y_{t}$. It is instructive to use a dedicated ARIMA software procedure for estimation. We used SAS PROC ARIMA procedure for model estimation by removing the default boundary constraint and trying different starting values for $\theta$ including $\theta=0.99$. Table 4 shows close correspondence between $\operatorname{AR}(p)$ coefficients and $\operatorname{ARMA}(p, 1)$ coefficients except for cases where an AR unit root is likely to be present. In stationary cases $\hat{\theta}$ turns out to be almost unity. This means that the size distortion we noticed in the Monte Carlo experiment resulting from under estimation of $\theta$ may not be a serious problem in practice.

The cases where an AR unit root is likely to be present are marked with a ${ }^{*}$ under $\mathrm{z}(\mathrm{MA})$ column in Table 4. In these cases there is no close correspondence between the coefficients estimated from models fitted to $y_{t}$ and $\Delta y_{t}$. In fact, the coefficients from $\Delta y_{t}$ are less precisely estimated because of the possible common factor problem arising from unit roots in AR and MA polynomials. For this reason, we also report the estimates from $\operatorname{ARMA}(p-1,1)$ models after eliminating the AR unit root and insignificant coefficients. These are given in rows immediately below these AR unit root cases. Although the coefficient estimates are very different the conclusion remains the same that these series are non-stationary. It is also worth noting that when an AR unit root is present, $\hat{\theta}$ lies well below unity as is observed in many other studies. This 
Table 4: Stationarity test on APC. Quarterly data ending in 2013 are from IFS and OECD databases. Tests are based on $\log (\mathrm{APC})=\log (C / Y)$, where $C$ is real consumption expenditure and $Y$ is real GDP, seasonally adjusted. For the Johansen test no means rejection of cointegration between $\log (\mathrm{C})$ and $\log (\mathrm{Y})$ with the cointegrating vector $(1,-1)$. The VAR lag order was selected based on BIC. The null for ADF and Johansen is non-stationarity of $\log (\mathrm{APC})$ and that for KPSS and $z(\mathrm{MA})$ is stationarity. A* means significant at the $5 \%$ level. For these cases under $\mathrm{z}(\mathrm{MA})$, results are reported by fitting both $\operatorname{ARMA}(p, 1)$ and $\operatorname{ARMA}(p-1,1)$ models. Number of stationary series according to: ADF: 5, Johansen: 6, KPSS: 8; z(MA): 15 including German APC which is stationary at the $1 \%$ level.

\begin{tabular}{|c|c|c|c|c|c|c|c|c|}
\hline Country & $\mathrm{T}$ & AR Lags & $\begin{array}{l}\operatorname{AR}(p) \text { fit to } y_{t}: \\
\text { Coefficients }\end{array}$ & $\begin{array}{l}\operatorname{ARMA}(p, 1) \text { fit to } \Delta y_{t}: \\
\text { Coefficients }\end{array}$ & $\mathrm{ADF}$ & Johansen & KPSS & $\begin{array}{c}\mathrm{z}(\mathrm{MA}) \\
m=4\end{array}$ \\
\hline Australia & 216 & 1 & 0.94 & $0.95,1.00$ & -2.65 & yes & 0.19 & 0.60 \\
\hline Austria & 196 & $1,2,3$ & $0.61,0.17,0.11$ & $0.62,0.18,0.12,0.99$ & $-3.21^{*}$ & no & 0.15 & -1.16 \\
\hline Belgium & 136 & 1 & 0.98 & $\begin{array}{c}-0.45,-0.36 \\
0.04\end{array}$ & $\begin{array}{l}-1.31 \\
-\end{array}$ & no & $\begin{array}{c}0.94^{*} \\
-\end{array}$ & $\begin{array}{l}-6.25^{*} \\
-6.17^{*}\end{array}$ \\
\hline Canada & 228 & 1 & 0.98 & 0.98 & -1.95 & no & $0.62^{*}$ & -0.17 \\
\hline enmark & 14 & 1 & & 0.97 & -2 & no & 0.6 & -1.28 \\
\hline nland & 17 & 1,4 & $0.79,0.16$ & $0.82,0.19,1.00$ & & no & 0.2 & -0.80 \\
\hline ance & 14 & 1 & 0.97 & 0.98 & & no & 0.22 & -0.16 \\
\hline ermany & 216 & 1,3 & $0.74,0.18$ & $0.74,0.18,1.00$ & -2 & yes & $1.05^{*}$ & $-1.71^{*}$ \\
\hline aly & 17 & 1,4 & $.82,0.10$ & $0.78,0$ & -3.0 & yes & $1.14^{*}$ & -0.02 \\
\hline Japan & 21 & 1 & 0.96 & 0.98 & -1 & no & 0.4 & -0.04 \\
\hline Korea, South & 196 & 1,2 & $0.83,0.17$ & $\begin{array}{c}0.12,0.02,0.32 \\
0.20\end{array}$ & $\begin{array}{l}-1.90 \\
-\end{array}$ & no & $\begin{array}{c}1.56^{*} \\
-\end{array}$ & $\begin{array}{l}-7.38^{*} \\
-7.30^{*}\end{array}$ \\
\hline Mexico & 132 & 1 & 0.90 & 0.89 & -2.5 & no & 0.41 & -0.21 \\
\hline Netherlands & 148 & 1,2 & $0.55,0.45$ & $\begin{array}{l}0.41,0.39,0.92 \\
\quad-0.41,0.06\end{array}$ & $\begin{array}{l}-1.5 \\
-\end{array}$ & $\begin{array}{l}\text { no } \\
-\end{array}$ & $\begin{array}{c}1.17^{*} \\
-\end{array}$ & $\begin{array}{l}-2.33^{*} \\
-6.66^{*}\end{array}$ \\
\hline $\mathrm{N}$ & 108 & 1 & & 0.7 & $-2.90^{*}$ & yes & 0.33 & -0.56 \\
\hline Norway & 212 & 1,2 & $0.75,0.23$ & $\begin{array}{c}0.15,0.11,0.93 \\
0.22\end{array}$ & $\begin{array}{l}-1.49 \\
-\end{array}$ & no & $\begin{array}{c}1.47^{*} \\
-\end{array}$ & $\begin{array}{l}-7.24^{*} \\
-7.23^{*}\end{array}$ \\
\hline Spain & 176 & 1,4 & $0.85,0.14$ & $\begin{array}{c}0.71,0.10,0.88 \\
0.61,0.83\end{array}$ & $\begin{array}{l}-0.35 \\
-\end{array}$ & $\begin{array}{c}\text { no } \\
-\end{array}$ & $\begin{array}{c}1.62^{*} \\
-\end{array}$ & $\begin{array}{l}-4.51^{*} \\
-6,00^{*}\end{array}$ \\
\hline & 136 & $1,2,4$ & $70,0.33,-0.18$ & $0.67,0.33,-0.21,1.00$ & $-2.89^{*}$ & no & $0.73^{*}$ & -0.41 \\
\hline Switzerland & 176 & $1,2,3$ & $0.64,0.49,-0.21$ & $0.65,0.49,-0.20,1.00$ & -2 & $\mathrm{n}$ & 0.22 & -0.73 \\
\hline Turkey & 108 & 1 & & $0.60,1.00$ & $-4.54^{*}$ & ye & $0.66^{*}$ & 0.47 \\
\hline & 228 & $1,2,3$ & $0.70,0.13 .0 .15$ & $0.70,0.13,0.15,1.00$ & -1.51 & yes & $0.56^{*}$ & 1.19 \\
\hline US & 228 & 1 & 1.00 & $\begin{array}{c}0.60,0.70 \\
0.13\end{array}$ & $\begin{array}{l}-0.58 \\
-\end{array}$ & $\begin{array}{c}\text { no } \\
-\end{array}$ & $\begin{array}{c}1.84^{*} \\
-\end{array}$ & $\begin{array}{l}-7.21^{*} \\
-7.85^{*}\end{array}$ \\
\hline
\end{tabular}

renders more power to the test.

Table 4 shows that the sum of the AR coefficients is above 0.9 in 16 of the 21 cases. The ADF test renders I(1) verdict to all these $16 \log (\mathrm{APC})$ series. The Johansen test and the KPSS test fair better, recognizing six and eight cases respectively as cointegrating relationships. However, these cases do not necessarily overlap. The $\mathrm{z}(\mathrm{MA})$ test, on the other hand, takes 14 of the $21 \log (\mathrm{APC})$ series to be stationary. At the $1 \%$ level German APC is also stationary, thus giving a total of 15 stationary cases. It rejected stationarity only when the sum of the AR coefficients is very close to unity $\left(\sum \geq 0.98\right)$ and when a local trend dominated the series (Belgium, South Korea, the Netherlands, Norway, Spain and the USA). For these six cases the other three tests also lead to 

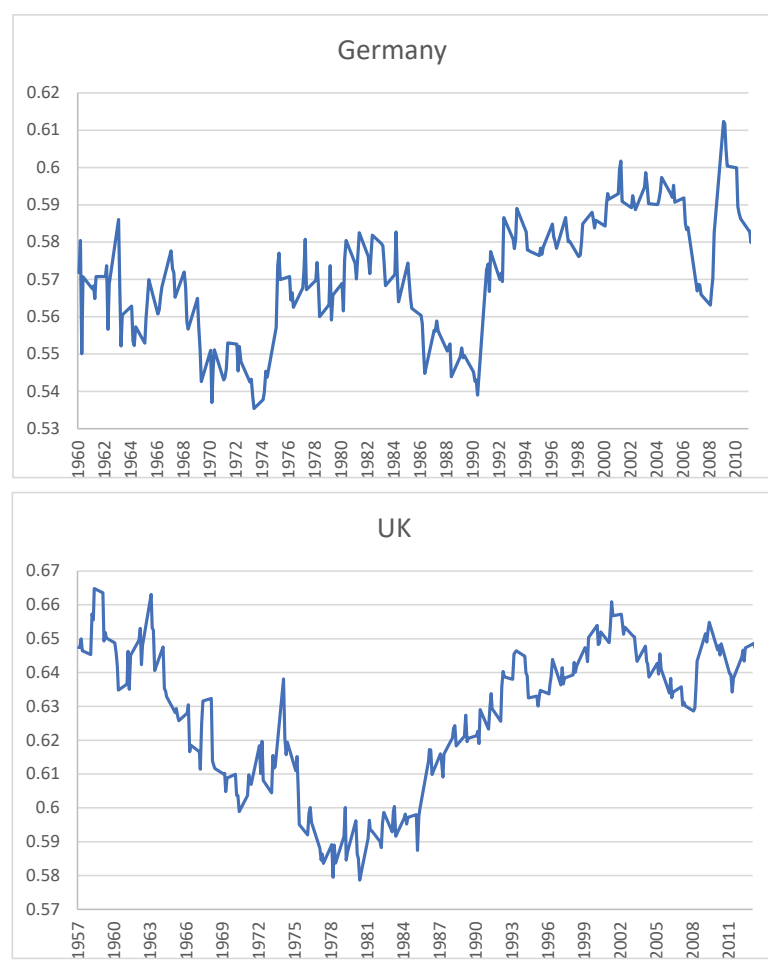

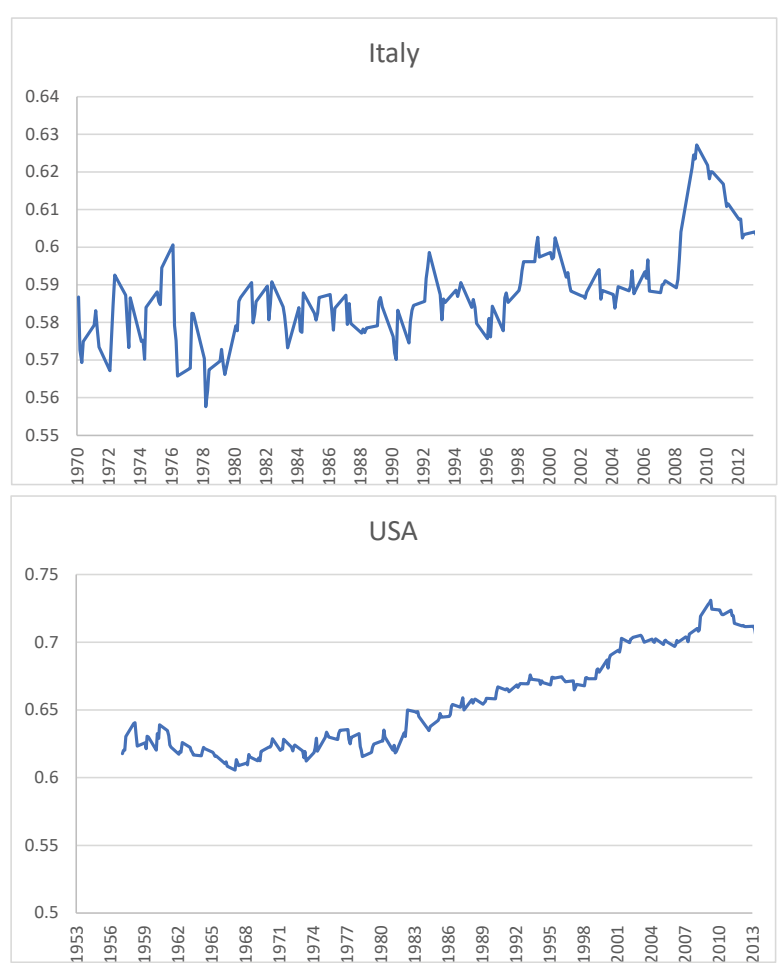

Figure 1: APC of selected countries to highlight the influence of local trends on test outcomes. The US $\log (\mathrm{APC})$ is non-stationary by all four tests and the other three are stationary by Johansen and $\mathrm{z}(\mathrm{MA})$ tests.

the same conclusion. When a local trend is not dominant the $\mathrm{z}(\mathrm{MA})$ test renders $\mathrm{I}(0)$ verdict even when the sum of the AR coefficients is large. To highlight these points Figure 1 shows four APC series (Germany, Italy, the UK and the USA). The US series has a dominant local trend component that leads all the tests to reject the stationarity hypothesis. In the other three cases there are local trend components including a jump in APC as a result of falling incomes after the global financial crisis in 2008. Despite the presence of these local trends the Johansen and z(MA) tests support the stationarity of these $\log (A P C)$ series. The ADF test supports the stationarity of the Italian series. In general, local trends seem to affect the ADF, Johansen and KPSS tests more than the $\mathrm{z}(\mathrm{MA})$ test. Rejecting the null of stationarity of important ratios like APC is an indication of the interplay of other variables that need to be considered instead of taking such ratios to be $\mathrm{I}(1)$ processes.

\section{Conclusion}

This exercise addresses three important issues. First, it highlights the importance of formulating tests based on the null of stationarity. What is of general importance is whether a regression relationship produces stationary residuals regardless of the nature of non-stationarities of the individual series. Moreover, an AR unit root in an individual series is hard to pin down because an apparent unit root could be a manifestation of some other forms of non-stationarity. We present an MA unit root test based on the null of stationarity. Unlike the AR unit root which is a behavioral outcome, the MA unit root is created by over-differencing and therefore easier to 
pin down.

Although testing for an MA unit root is not new to the literature, the existing tests require non-standard distributions. The second important aspect of the exercise is that the proposed test brings us back to the normal distribution and makes specifications searches easier.

The third aspect of the exercise is that the test procedure entails a mechanism to increase power without necessarily having to increase the sample size. This addresses the problem of low power at near null alternatives of many AR unit root tests that are currently available. All this is evident in the application; the $\mathrm{z}(\mathrm{MA})$ test favors stationarity of 15 out of $21 \log (A P C)$ series whereas the other three tests examined are mostly in favor of non-stationarity. The empirical results in general highlight that when an AR unit root is present the MA parameter $\theta$ in the first difference model is likely to lie well below unity. This renders more power to the test.

\section{Acknowledgement}

The authors would like to mention gratefully the research and travel grants provided by the Faculty of Arts and Social Sciences and the Singapore Center for Applied and Policy Economics, National University of Singapore. Thanks are also due to Mervyn Silvapulle for showing us an alternative proof to the theorem in the paper and Gu Jiaying, Choy Keen Meng and seminar participants at Singapore Management University, Monash University, LaTrobe University, Griffith University and the Australasian Meeting of the Econometric Society for their valuable comments on an earlier draft of the paper. Valuable comments by the referees and the editor of the journal were immensely helpful in further improvement of the results of the paper.

\section{Appendix A}

\section{Proof of the Theorem}

Proof. Here we derive the asymptotic distribution of $\sqrt{T}\left(\hat{\sigma}_{m, T}^{2}-2 \hat{\sigma}_{T}^{2}\right)$ under the null hypothesis $\theta=1$. Assuming $(p+m)$ pre-sample values are available we can run the model in (2) to obtain consistent estimates of the parameters, obtain the estimated residuals $\hat{u}_{t}$, and compute $\hat{\sigma}_{T}^{2}=(1 / T) \sum_{t=1}^{T} \hat{u}_{t}^{2}, \hat{V}_{t}=\hat{u}_{t}-\hat{\theta}^{m} \hat{u}_{t-m}, \hat{\sigma}_{m, T}^{2}=(1 / T) \sum_{t=1}^{T} \hat{V}_{t}^{2}$. We have to work on the expression:

$$
\sqrt{T}\left(\hat{\sigma}_{m, T}^{2}-2 \hat{\sigma}_{T}^{2}\right)=\sqrt{T}\left[\left(\hat{\sigma}_{m, T}^{2}-2 \sigma^{2}\right)-2\left(\hat{\sigma}_{T}^{2}-\sigma^{2}\right)\right] .
$$

It is well established that $\sqrt{T}\left(\hat{\sigma}_{T}^{2}-\sigma^{2}\right) \stackrel{d}{\longrightarrow} N\left(0,\left(\mu_{4}-\sigma^{4}\right)\right)$. (See, for example, Hamilton, 1994, p.212.) We can establish a similar result for $\sqrt{T}\left(\hat{\sigma}_{m, T}^{2}-2 \sigma^{2}\right)$. However, since our interest is in the difference in (6) we can derive its asymptotic distribution in a direct manner.

Given the T-consistency of $\hat{\theta}$ under the null $\theta=1$, in large samples the aggregation polynomial $\theta(L)$ can be written as $\theta(L)=\left(1+L+, \ldots, L^{m-1}\right)$ and model (4) can be written as

$$
\Delta_{m} y_{t}=m \beta+\phi_{1} \Delta_{m} y_{t-1}+\ldots+\phi_{p} \Delta_{m} y_{p}+V_{t}
$$

where $\Delta_{m} z_{t}=z_{t}-z_{t-m}$ and $V_{t}=u_{t}-u_{t-m}$. Now defining $\mathbf{x}_{t}=\left(1, \Delta y_{t-1}, \ldots, \Delta y_{t-p}\right)^{\mathrm{T}}$, $\mathbf{x}_{a t}=\left(1, \Delta_{m} y_{t-1}, \ldots, \Delta_{m} y_{t-p}\right)^{\mathrm{T}}$ and $\boldsymbol{\beta}=\left(\beta^{+}, \phi_{1}, \ldots, \phi_{p}\right)^{\mathrm{T}}$, where $\beta^{+}=m \beta$, we can write $(5)$ as $\Delta_{m} y_{t}=\mathbf{x}_{a t}^{\mathrm{T}} \boldsymbol{\beta}+V_{t}$ or in full observation matrix format as

$$
\mathbf{y}_{a}=\mathbf{X}_{a} \boldsymbol{\beta}+\mathbf{V}
$$


where $\mathbf{y}_{a}$ is the observation vector of $\Delta_{m} y_{t}$ and the other terms defined conformably. Now we can obtain

$$
\hat{\mathbf{V}}=\mathbf{V}-\mathbf{X}_{a}(\hat{\boldsymbol{\beta}}-\boldsymbol{\beta}),
$$

and using the subscript $T$ to indicate the dependence on sample size we get

$$
\begin{aligned}
\hat{\sigma}_{m, T}^{2}=(1 / T) \hat{\mathbf{V}}_{T}^{\mathrm{T}} \hat{\mathbf{V}}_{T}= & (1 / T) \mathbf{V}_{T}^{\mathrm{T}} \mathbf{V}_{T}-(2 / T)\left(\hat{\boldsymbol{\beta}}_{T}-\boldsymbol{\beta}\right)^{\mathrm{T}} \mathbf{X}_{a T}^{\mathrm{T}} \mathbf{V}_{T} \\
& +\left(\hat{\boldsymbol{\beta}}_{T}-\boldsymbol{\beta}\right)^{\mathrm{T}}\left(\mathbf{X}_{a T}^{\mathrm{T}} \mathbf{X}_{a T} / T\right)\left(\hat{\boldsymbol{\beta}}_{T}-\boldsymbol{\beta}\right) \\
\stackrel{p}{\longrightarrow} & 2 \sigma^{2} .
\end{aligned}
$$

This result holds because $\left(\boldsymbol{\beta}_{T}-\boldsymbol{\beta}\right) \stackrel{p}{\longrightarrow} \mathbf{0}$ and it is assumed that $\left(\mathbf{X}_{a T}^{\mathrm{T}} \mathbf{X}_{a T} / T\right) \stackrel{p}{\longrightarrow} \mathbf{Q}_{a}$, a finite positive definite matrix, and as shown below $\mathbf{X}_{a T}^{\mathrm{T}} \mathbf{V}_{T} / T \stackrel{p}{\longrightarrow} \mathbf{c}$, a $((p+1) \times 1)$ vector of constants. This vector can be derived easily by noting $\mathbf{X}_{a T}^{\mathrm{T}} \mathbf{V}_{T} / T=T^{-1} \sum \mathbf{x}_{a t} V_{t}=$ $-T^{-1} \sum \mathbf{x}_{a t} u_{t-m}+o_{p}(1)$ and $\Delta_{m} y_{t}=\phi(L)^{-1} V_{t}=\psi(L) V_{t}$, where $\phi(L)^{-1}=\psi(L)=1+\psi_{1} L+$ $\psi_{2} L^{2}+\ldots$ The first term of $T^{-1} \sum \mathbf{x}_{a t} u_{t-m}$ leads to $T^{-1} \sum u_{t-m} \stackrel{p}{\longrightarrow} 0$. The pth term of $T_{a}^{-1} \sum \mathbf{x}_{a t} u_{t-m}$ is $T^{-1} \sum \Delta_{m} y_{t-p} u_{t-m}=T^{-1} \sum \psi(L)\left(u_{t-1}-u_{t-m-1}\right) u_{t-m}=T^{-1} \sum \psi_{m-p} u_{t-m}^{2}+$ $o_{p}(1) \stackrel{p}{\longrightarrow} \sigma^{2} \psi_{m-p}$. If $p>m, \psi_{-p}=0$.

Now consider $\sqrt{T}\left(\hat{\sigma}_{m, T}^{2}-2 \sigma^{2}\right)$. Multiplying (A4) through by $\sqrt{T}$ shows that the last term of (10) converges in probability zero and provides

$$
\begin{aligned}
\sqrt{T}\left(\hat{\sigma}_{m, T}^{2}-2 \sigma^{2}\right) & =\sqrt{T}\left(\mathbf{V}_{T}^{\mathrm{T}} \mathbf{V}_{T} / T-2 \sigma^{2}\right)-2 \sqrt{T}\left(\hat{\boldsymbol{\beta}}_{T}-\boldsymbol{\beta}\right)^{\mathrm{T}}\left(\mathbf{X}_{a T}^{\mathrm{T}} \mathbf{V}_{T} / T\right) \\
& =\sqrt{T}\left(\mathbf{V}_{T}^{\mathrm{T}} \mathbf{V}_{T} / T-2 \sigma^{2}\right)+o_{p}(1) .
\end{aligned}
$$

Note that $\hat{\boldsymbol{\beta}}_{T}-\boldsymbol{\beta}$ is $o_{p}(1)$ and $\mathbf{X}_{a T}^{\mathrm{T}} \mathbf{V}_{T} / \sqrt{T}$ is $O_{p}(1)$. In a similar way we get

$$
\begin{aligned}
\sqrt{T}\left(\hat{\sigma}_{T}^{2}-\sigma^{2}\right) & =\sqrt{T}\left(\mathbf{u}_{T}^{\mathrm{T}} \mathbf{u}_{T} / T-2 \sigma^{2}\right)-2 \sqrt{T}\left(\hat{\boldsymbol{\beta}}_{T}-\boldsymbol{\beta}\right)^{\mathrm{T}}\left(\mathbf{X}_{T}^{\mathrm{T}} \mathbf{u}_{T} / T\right) \\
& =\sqrt{T}\left(\mathbf{u}_{T}^{\mathrm{T}} \mathbf{u}_{T} / T-2 \sigma^{2}\right)+o_{p}(1) .
\end{aligned}
$$

Now from (11) and (12) we get

$$
\begin{aligned}
\sqrt{T}\left(\hat{\sigma}_{m, T}^{2}-2 \hat{\sigma}_{T}^{2}\right) & =(1 / \sqrt{T})\left(\sum\left(u_{t}-u_{t-m}\right)^{2}-\sum u_{t}^{2}\right)+o_{p}(1) \\
& =(1 / \sqrt{T}) \sum\left(-u_{t}^{2}-2 u_{t} u_{t-m}+u_{t-m}^{2}\right)+o_{p}(1)
\end{aligned}
$$

It is easily seen from (13) that $\sqrt{T}\left(\hat{\sigma}_{m, T}^{2}-2 \hat{\sigma}_{T}^{2}\right) \stackrel{p}{\longrightarrow} 0$. To derive its variance, let $\xi_{t}=-u_{t}^{2}-$ $2 u_{t} u_{t-m}+u_{t-m}^{2}$ and obtain

$$
\begin{aligned}
\operatorname{Var}\left\{(1 / \sqrt{T}) \sum \xi_{t}\right\} & =(1 / T)\left[E\left(\sum \xi_{t}\right)^{2}\right] \\
& =(1 / T)\left[\sum_{t=1}^{T} E\left(\xi_{t}^{2}\right)+2 \sum_{t=1}^{T} \sum_{k=1}^{t-1} E\left(\xi_{t} \xi_{t-k}\right)\right] \\
E\left(\xi_{t}^{2}\right) & =E\left[\left(-u_{t}^{2}-2 u_{t} u_{t-m}+u_{t-m}^{2}\right)\left(-u_{t}^{2}-2 u_{t} u_{t-m}+u_{t-m}^{2}\right)\right] \\
& =2 \mu_{4}+2 \sigma^{4}, \\
E\left(\xi_{t} \xi_{t-k}\right) & =E\left[\left(-u_{t}^{2}-2 u_{t} u_{t-m}+u_{t-m}^{2}\right)\left(-u_{t-m}^{2}-2 u_{t-m} u_{t-2 m}+u_{t-2 m}^{2}\right)\right] \\
& = \begin{cases}-\mu_{4}+\sigma^{4}, & k=m, \\
0, & k \neq m .\end{cases}
\end{aligned}
$$


and

$$
\begin{aligned}
\operatorname{Var}\left\{(1 / \sqrt{T}) \sum \xi_{t}\right\} & =(1 / T)\left[2 T\left(\mu_{4}+\sigma^{4}\right)+2 T\left(-\mu_{4}+\sigma^{4}\right)\right] \\
& =4 \sigma^{4}
\end{aligned}
$$

Therefore, from (13) and (17) we can see that $\operatorname{Var}\left(\sqrt{T}\left(\hat{\sigma}_{m, T}^{2}-2 \hat{\sigma}_{T}^{2}\right)\right) \stackrel{p}{\longrightarrow} 4 \sigma^{4}$. Furthermore, above results show that $\sqrt{T}\left(\hat{\sigma}_{m, T}^{2}-2 \hat{\sigma}_{T}^{2}\right)$ is a stationary ergodic process with covariance converging to $-\mu_{4}+\sigma^{4}$ at lag $m$ and to zero at other lags. Therefore, by the central limit theorem for stationary stochastic processes (Hamilton, 1994, Proposition 7.11 and White, 2001, Section 5.3), we can establish that $\sqrt{T}\left(\hat{\sigma}_{m, T}^{2}-2 \hat{\sigma}_{T}^{2}\right) \stackrel{d}{\longrightarrow} N\left(0,4 \sigma^{4}\right)$.

\section{Appendix B}

Table 5: Power of unit root tests at the $5 \%$ level and $T=100$. Reference model: $y_{t}=\alpha+\beta t+$ $\rho y_{t-1}+\varepsilon_{t}-\theta \varepsilon_{t-1}, \varepsilon_{t} \stackrel{i . i . d .}{\sim} \mathrm{N}\left(0, \sigma^{2}\right)$. When $T=100$ is not available, 200 is used and marked with

\begin{tabular}{|c|c|c|c|c|c|c|c|c|}
\hline $\begin{array}{l}\text { Name of } \\
\text { Authors }\end{array}$ & Year & Model Type & Test Type & $\begin{array}{l}\rho= \\
0.80\end{array}$ & $\begin{array}{l}\rho= \\
0.85\end{array}$ & $\begin{array}{ll}\rho= & \rho= \\
0.90 & 0.95\end{array}$ & $\begin{array}{c}\rho= \\
0.975\end{array}$ & Remarks \\
\hline \multicolumn{9}{|c|}{ (a) Non-stationary null $(\rho=1)$} \\
\hline $\begin{array}{l}\text { Dicky \& } \\
\text { Fuller }\end{array}$ & 1979 & $\begin{array}{l}\theta=0, \beta=0 \\
\theta=0, \beta=0\end{array}$ & $\hat{\rho}$ & $\begin{array}{l}0.86 \\
0.73\end{array}$ & & $\begin{array}{ll}0.30 & 0.10 \\
0.18 & 0.06\end{array}$ & & \multirow[t]{2}{*}{$\mathrm{DF}$ test, $\mathrm{AR}(1)$ process } \\
\hline Bhargava & 1986 & $\theta=0, \beta=0$ & DW & 0.73 & 0.49 & 0.250 .10 & & \\
\hline $\begin{array}{l}\text { Phillips \& } \\
\text { Perron }\end{array}$ & 1988 & $\begin{array}{c}\theta=0, \beta=0 \\
\theta=0.8, \beta=0 \\
\theta=0, \beta=0 \\
\theta=0.8, \beta=0\end{array}$ & $\begin{array}{c}\mathrm{t} \\
\mathrm{t} \\
\mathrm{Z}(\mathrm{t}) \\
\mathrm{Z}(\mathrm{t})\end{array}$ & & $\begin{array}{l}0.47 \\
0.30 \\
0.69 \\
0.35\end{array}$ & & & $\begin{array}{l}\text { ADF, Said \& Dicky } 1984 \\
\text { ADF } \\
\text { PP } \\
\text { PP }\end{array}$ \\
\hline $\begin{array}{l}\text { Pantula \& } \\
\text { Hall }^{*}\end{array}$ & 1991 & $\begin{array}{c}\theta=0, \beta=0 \\
\theta=0.8, \beta=0\end{array}$ & $\begin{array}{l}\text { IV } \\
\text { IV }\end{array}$ & & & & $\begin{array}{c}0.09- \\
0.33 \\
0.01- \\
0.35\end{array}$ & $\begin{array}{l}\text { Range of IV estimates. In } \\
\text { general power }>0.05\end{array}$ \\
\hline $\begin{array}{l}\text { DeJong, } \\
\text { Nankervis \& } \\
\text { Savin }\end{array}$ & 1992 & $\theta=0, \beta \neq 0$ & $\begin{array}{c}\tau(\rho) \\
\mathrm{F}(\beta, \rho)\end{array}$ & $\begin{array}{l}0.75 \\
0.65\end{array}$ & $\begin{array}{l}0.49 \\
0.39\end{array}$ & $\begin{array}{ll}0.24 & 0.10 \\
0.19 & 0.08\end{array}$ & & $\begin{array}{l}\text { For starting value } 0 \text {. Power } \\
\text { drops slightly as starting } \\
\text { value increases. }\end{array}$ \\
\hline Blough & 1992 & $\theta=0, \beta=0$ & $\mathrm{ADF}, \mathrm{IV}$ & & & & & $\begin{array}{l}\text { Graphical presentation. } \\
\text { Power drops } \\
\text { to } 5 \% \text { for } r>0.5\end{array}$ \\
\hline $\begin{array}{l}\text { Schmidt } \\
\text { \& Phillips }\end{array}$ & 1992 & $\theta=0, \beta \neq 0$ & LM & & & 0.270 .11 & & $\begin{array}{l}\text { Reported is highest power } \\
\text { under different specifications }\end{array}$ \\
\hline Choi & 1992 & $\theta=0, \beta \neq 0$ & $\mathrm{DH}$ & 0.97 & 0.84 & $0.54 \quad 0.24$ & & Durbin-Hausman \\
\hline $\begin{array}{l}\text { Lee \& } \\
\text { Schimidt }\end{array}$ & 1994 & $\theta=0.8, \beta=0$ & IV & & & 0.22 & & $\begin{array}{l}\text { Compares Hall-IV } \\
\text { with SP-IV }\end{array}$ \\
\hline
\end{tabular}
an asterisk against author's name. 
Pantula,

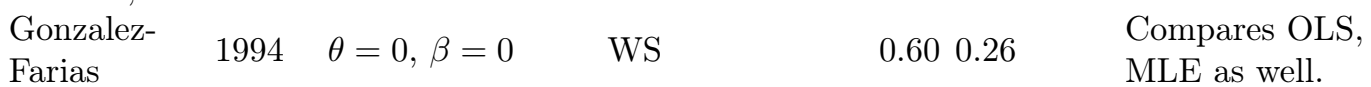

\& Fuller

\begin{tabular}{|c|c|c|c|c|c|c|}
\hline $\begin{array}{l}\text { Yap \& } \\
\text { Reinsel* }\end{array}$ & 1995 & $\begin{array}{c}\theta=0, \beta=0 \\
\theta=0.8, \beta=0\end{array}$ & $\begin{array}{l}\text { LR } \\
\text { LR }\end{array}$ & $\begin{array}{c}1.00 \\
-\end{array}$ & $\begin{array}{ll}0.82 & 0.33 \\
0.74 & 0.56\end{array}$ & \\
\hline Leybourne & 1995 & $\theta=0, \beta=0$ & DFmax & 0.88 & 0.34 & \\
\hline $\begin{array}{l}\text { Perron } \\
\& \mathrm{Ng}^{*}\end{array}$ & 1996 & $\theta=0.8, \beta=0$ & $\begin{array}{l}\operatorname{MZ}(\rho) \\
\operatorname{MSB} \\
\operatorname{MZ}(\mathrm{t})\end{array}$ & & $\begin{array}{ll}0.75 & 0.42 \\
0.79 & 0.46 \\
0.63 & 0.30\end{array}$ & Modified PP \\
\hline $\begin{array}{l}\text { Elliot, } \\
\text { Rothenberg } \\
\text { \& Stock }\end{array}$ & 1996 & $\theta=0.8, \beta=0$ & $\mathrm{t}$ & 0.51 & 0.300 .15 & $\begin{array}{l}\text { Power at } \rho=0.95 \\
\text { not very different } \\
\text { across models }\end{array}$ \\
\hline $\begin{array}{l}\text { Hwang } \\
\text { \& Schmidt }\end{array}$ & 1996 & $\theta=0, \beta \neq 0$ & GLS & 0.280 .1 & & $\begin{array}{l}\text { Power is roughly } \\
\text { similar across different } \\
\text { tests reported }\end{array}$ \\
\hline \multicolumn{7}{|c|}{ Non-stationary null: Structural breaks } \\
\hline $\begin{array}{l}\text { Lanne \& } \\
\text { Lutkepohl }\end{array}$ & 2002 & \multicolumn{2}{|c|}{$\begin{array}{c}\text { Perron } \\
\text { Perron \& Vogelsang } \\
\text { Amsler \& Lee } \\
\text { Schmidt \& Phillips } \\
\text { Lanne \& Lutkepohl }\end{array}$} & & $\begin{array}{l}0.21 \\
0.14 \\
0.12 \\
0.09 \\
0.23\end{array}$ & $\begin{array}{l}\text { Known break, level shift. } \\
\text { Power is very similar for } \\
\text { slope change. See the article } \\
\text { for model specification. }\end{array}$ \\
\hline $\begin{array}{l}\text { Lanne, } \\
\text { Lutkepohl \& } \\
\text { Saikonen }\end{array}$ & 2003 & \multicolumn{2}{|c|}{$\begin{array}{l}\text { Test } 1 \text {, drift } \\
\text { Test } 2 \text {, drift } \\
\text { Test } 3 \text {, trend } \\
\text { Test } 3 \text {, trend }\end{array}$} & & $\begin{array}{l}0.28 \\
0.20 \\
0.23 \\
0.18\end{array}$ & $\begin{array}{l}\text { Unknown break, level shift. } \\
\text { Power is very similar for } \\
\text { slope change. See the article } \\
\text { for model specification. }\end{array}$ \\
\hline $\begin{array}{l}\text { Costantini } \\
\& \text { Sen }\end{array}$ & 2016 & \multicolumn{2}{|c|}{ Three tests } & & $0.1-0.5$ & $\begin{array}{l}\text { Level shift } \\
\text { and slope change }\end{array}$ \\
\hline
\end{tabular}

(b) Stationary null $(\rho=1, \theta=1)$

\begin{tabular}{|c|c|c|c|c|c|c|c|}
\hline Park & 1990 & & J1 test & & & & No simulation results \\
\hline $\begin{array}{l}\text { Kwiatkowski, } \\
\text { Phillips, } \\
\text { Schmidt \& } \\
\text { Shin }\end{array}$ & 1992 & $\begin{array}{l}\beta=0 \\
\beta=0 \\
\beta=0 \\
\beta \neq 0 \\
\beta \neq 0 \\
\beta \neq 0\end{array}$ & $\begin{array}{c}\eta(\mu) l 0 \\
\eta(\mu) l 4 \\
\eta(\mu) l 12 \\
\eta(\mu) l 0 \\
\eta(\mu) l 4 \\
\eta(\mu) l 12\end{array}$ & & $\begin{array}{l}0.59 \\
0.51 \\
0.38 \\
0.35 \\
0.28 \\
0.17\end{array}$ & $\begin{array}{l}0.17 \\
0.15 \\
0.10 \\
0.05 \\
0.05 \\
0.04\end{array}$ & $\begin{array}{l}\text { KPSS test. The test } \\
\text { basically involves testing } \\
\sigma_{\eta}^{2}=0 \text { in model (1) in } \\
\text { Section } 3 .\end{array}$ \\
\hline $\begin{array}{l}\text { Saikkonen } \\
\text { \& Luukkonen }\end{array}$ & 1993 & $\beta=0$ & $\mathrm{R} 2$ & 0.810 .71 & $0.56 \quad 0.32$ & & $\begin{array}{l}\text { Authors also consider } \\
\text { non-white errors. }\end{array}$ \\
\hline Breitung & 1994 & $\beta=0$ & $\begin{array}{l}\text { Spectral } \\
\text { Var diff } \\
\text { Tanaka }\end{array}$ & $\begin{array}{l}0.04 \\
0.87 \\
0.86\end{array}$ & $\begin{array}{ll}0.03 & 0.03 \\
0.43 & 0.16 \\
0.62 & 0.32\end{array}$ & & \\
\hline $\begin{array}{l}\text { Leybourne } \\
\text { and McCabe }\end{array}$ & $1994 \mathrm{E}$ & ended KPSS & $\begin{array}{l}s(\alpha) p=1 \\
s(\alpha) p=2 \\
s(\alpha) p=3\end{array}$ & & $\begin{array}{l}0.61 \\
0.59 \\
0.56\end{array}$ & $\begin{array}{l}0.17 \\
0.17 \\
0.16\end{array}$ & $\begin{array}{l}\text { Show that KPSS is subject } \\
\text { to severe size distortions in } \\
\text { general ARIMA cases. }\end{array}$ \\
\hline
\end{tabular}




\begin{tabular}{lllll} 
& & $w 1 l=2$ & 0.47 & \\
Choi & & & \\
& & $w 1 l=3$ & 0.38 & Power remains low for other \\
& & $w 1 l=4$ & 0.27 & lags on w2 test \\
& & $w 1 l=5$ & 0.06 & \\
\hline
\end{tabular}

\section{References}

Abeysinghe T (1998). Forecasting Singapore's quarterly GDP with monthly external trade. International Journal of Forecasting, 14(4): 505-513.

Abeysinghe $\mathrm{T}$ (2000). Modeling variables of different frequencies. International Journal of Forecasting, 16(1): 117-119.

Abeysinghe T, Rajaguru G (2004). Quarterly real GDP estimates for China and ASEAN4 with a forecast evaluation. Journal of Forecasting, 23(6): 431-447.

Breidt FJ, Davis RA, Hsu NJ, Rosenblatt M, et al. (2006). Pile-up Probabilities for the Laplace Likelihood Estimator of a Non-invertible First Order Moving Average, volume 52 of Lecture Notes-Monograph Series, 1-19. Institute of Mathematical Statistics.

Breitung J (1994). Some simple tests of the moving-average unit root hypothesis. Journal of Time Series Analysis, 15(4): 351-370.

Breitung J (1995). Modified stationarity tests with improved power in small samples. Statistical Papers, 36(1): 77-95.

Choi I (1994). Residual-based tests for the null of stationarity with applications to US macroeconomic time series. Econometric Theory, 10(3/4): 720-746.

Davis RA, Dunsmuir WT (1996). Maximum likelihood estimation for MA(1) processes with a root on or near the unit circle. Econometric Theory, 12(1): 1-29.

Hamilton JD (1994). Time Series Analysis. Princeton University Press.

Harsha S, Ismail B (2017). Improved test for detecting explosive bubbles. Journal of Data Science, 15(3): 495-508.

Harvey AC (1989). Forecasting, Structural Time Series Models and the Kalman Filter. Cambridge University Press.

Kim JH, Choi I (2017). Unit roots in economic and financial time series: A re-evaluation at the decision-based significance levels. Econometrics, 5(3): 41.

King RG, Plosser CI, Stock JH, Watson MW (1991). Stochastic trends and economic fluctuations. The American Economic Review, 81(4): 819-840.

Kwiatkowski D, Phillips PC, Schmidt P, Shin Y, et al. (1992). Testing the null hypothesis of stationarity against the alternative of a unit root. Journal of Econometrics, 54(1-3): 159-178.

Leybourne SJ, McCabe BP (1994). A consistent test for a unit root. Journal of Business 63 Economic Statistics, 12(2): 157-166.

Lo AW, MacKinlay AC (1988). Stock market prices do not follow random walks: Evidence from a simple specification test. The Review of Financial Studies, 1(1): 41-66.

Lo AW, MacKinlay AC (1989). The size and power of the variance ratio test in finite samples: A Monte Carlo investigation. Journal of Econometrics, 40(2): 203-238.

Maddala GS, Kim IM (1998). Unit Roots, Cointegration, and Structural Change. Cambridge University Press.

Phillips PC (2010). Unit roots. In: Macroeconometrics and Time Series Analysis (SN Durlau, fLawrence E Blume, eds.), 347-368. Springer. 
Rajaguru G (2004). Impact of systematic sampling on causality in the presence of unit roots. Economics Letters, 84(1): 127-132.

Rajaguru G, Abeysinghe T (2008). Temporal aggregation, cointegration and causality inference. Economics Letters, 101(3): 223-226.

Rajaguru G, O'Neill M, Abeysinghe T (2018). Does systematic sampling preserve granger causality with an application to high frequency financial data? Econometrics, 6(2): 31.

Reschenhofer E (2004). Unexpected features of financial time series: Higher-order anomalies and predictability. Journal of Data Science, 2(1): 1-15.

Saikkonen P, Luukkonen R (1993). Testing for a moving average unit root in autoregressive integrated moving average models. Journal of the American Statistical Association, 88(422): 596-601.

Tanaka K (1990). Testing for a moving average unit root. Econometric Theory, 6(4): 433-444.

Wang H, Yu Y, Li M (2010). On intraday shanghai stock exchange index. Journal of Data Science, 8(3): 413-427.

White H (2001). Asymptotic Theory for Econometricians: Revised Edition. Emerald Group Publishing Limited. 